\title{
A modest proposal to the Department of Education and Science
}

THERE is by no means enough lobbying of government on behalf of science. That was the challenge thrown out last week by Mrs Shirley Williams, Britain's Secretary of State for Education and Science, at a gathering of the Association of British Science Writers. The Arts, for which she is also responsible, lobby regularly and aggressively; science's voice is rarely heard. This will come as a surprise to many scientists who have assumed that lobbying would be unwelcome and counterproductive. But the challenge is not just to scientists; it is to Mrs Williams herself to find ways of opening up the London machinery to the community at large so that access to decision-makers becomes easier to achieve.

That British scientists don't do enough to express their opinions is undeniable. Certainly when an issue like the payment of CERN's subscription comes up there is a great flurry of activity, but for the most part the British scientist is totally silent-content, presumably, with zero growth rates and a secure job. Maybe the assumption is that the media will look after all questions concerned with policy and will spot all issues which ought to be raised; and then, when there is nothing in Nature, New Scientist or the Times Higher Education Supplement, it is assumed that there is really nothing to worry about. This would be a dangerous assumption; the media cannot hunt out what it knows nothing about, and certainly in the past few years the number of individual scientists who have approached us with a request that we should look into something or pursue a particular campaign is pathetically small.

Or maybe it is widely believed that worthy bodies like the Advisory Board for the Research Councils or the individual research councils themselves adequately look after the interests of science. The trouble with that assumption is that these bodies already have a fairly clear and well-charted relationship with the Department of Education and Science, and this allows relatively limited scope for anything resembling lobbying, which would, in any case, have to be done by chairmen themselves. What, presumably, Mrs Williams is looking for is a regular flow of opinion of diverse sorts, not just from research council heads, on how support for science should develop.

It would be too easy, however, to lay the blame for the lack of lobbying entirely on apathy in the country. That apathy has very largely been fostered by the way in which British society divides its institutions so scrupulously. There is Parliament. There is the civil service. There is the law. There is industry and commerce. There is the military. There is the academic world. And there is the press. All too rarely do people find it easy to cross these frontiers and live happily in two or more camps either concurrently or consecutively, and as a result public life suffers through narrowed horizons.

Obviously there is no simple remedy to this. Oversecure career prospects and innate beliefs that certain ways of earning a living are superior to others are not going to be done away with overnight. But there is some positive action Mrs Williams could take to get to hear the scientist's voice; she could create a post for a distinguished scientist who with a small staff could act as the department's ears and eyes into the scientific community-and not just academics. Maybe such a person would be called Chief Scientist, but his or her function would be rather different from those of chief scientists in other ministries. In many ways the job of being a link with practising scientists used to be performed by the government's chief scientific adviser, but now that this position has been allowed to lapse there is no one to whom scientists can turn in a personal capacity. The department's chief scientist ought to fulfil that role, but in doing so ought to be highly mobile. The attractions of life in London close to the corridors of power are obvious, but the right person would not be bound to an office but would be regularly on the road, thereby not just hearing what institutions and professional bodies have to say, but more importantly seeking out the opinions of individuals. 